regardless of financial considerations. Finally, organizations need to recognize that these decisions may have unforeseen consequences and be prepared to respond to these new circumstances.

The decision to move our meeting was announced to our membership on Friday, March 2, 2012. Virtually all of the feedback from our members has supported this decision. Many members have offered to help the organization address the financial shortfall that has been created, and we are considering options for donations to a new Principle and Diversity Fund. But we recognize that our decision has substantial implications for our choice of meeting locations in the future; numerous locales have laws or ordinances that some or all of our members will find abhorrent. ADFM is committed to defining an explicit process that will be used to select future meeting sites and to monitor that decision after it's been made.

Although Alabama is the state with the most draconian immigration law, other states have or are considering passing similar laws. In this era of political and social polarization, all nonprofit organizations will need to identify core values and principles that can be relied upon to guide important decisions relating to issues of social justice and welfare of our members. Richard Wender, MDi Tom Campbell, MDi

Barbara Thompson, MD, Ardis Davis, MSW This commentary was written by the ADFM Executive Committee

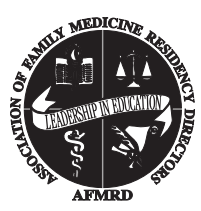

From the Association of Family Medicine Residency Directors

Ann Fam Med 2012;10:270-271. doi:10.1370/afm.1409.

\section{EDUCATION GAPS BETWEEN FAMILY PHYSICIANS AND LICENSED NURSE PRACTITIONERS}

As millions of Americans gain coverage for medical care in the coming years and as the need for primary care in patient-centered medical home (PCMH) models increases, our medical homes will need to provide more access to care. One such method is through advanced physician extenders which include physician assistants and nurse practitioners. Many entities are talking about allowing Advanced Registered Nurse Practitioners (ARNPs) work more independently without physician involvement. However, the vast difference in clinical training between family physicians and ARNPs is significant. Also, an effective provider in a $\mathrm{PCMH}$ is expected to manage without consultation a broad spectrum of disease. Therefore, practices without physician counterparts could lead to a tier of primary care that is limited in its effectiveness. ARNPs are a tremendous asset in providing some primary care services, ideally partnered with physicians in group settings, but have significant limitations when independently evaluating and managing undifferentiated patients due to the superficial coverage of medical topics during their training. The skill sets are complementary to each other, but not equal.

ARNP schools exhibit a wide variation of training standards from school to school and from state to state. There is no national accreditation body like the Accreditation Counsel for Graduate Medical Education (ACGME) that monitors advanced nursing profession schools or creates national standards for clinical experiences. Without a similar structure to the ACGME, it is impossible to assess the quality of the education across these various schools.

The diagnostic challenges primary care physicians face on a daily basis require they have extensive clinical exposure in order to perform efficiently. The depth of knowledge required to filter undifferentiated patients' complaints and to understand the subtleties of management is vast. The average family medicine physician has 21,000 total hours of training, most of it with clear patient management responsibilities and decreasing levels of supervision. The total hours of training a nurse practitioner receives is 2,300 to 5,300 hours depending on the advanced nursing program, and much of the clinical training is observational. Many states only require a 30-day observation period of a licensed active physician before an ARNP can deliver care unsupervised. Grandfathering people into independent practice would be like grandfathering a family physician into a subspecialty after doing a month of observation in that specialty.

In the end, to practice independently, one should be judged by those who have the experience and background to make that assessment. Family physicians are the experts of primary care in this country and our understanding of what it takes to practice competently and independently is quite thorough. Family physician faculty that teach residents are skilled at making such assessments.

We believe there are excellent roles for physician extenders who work in collaborative settings with physicians, enabling more independence for the physician extenders. The medical team in the PCMH has key roles for Physician Assistants and ARNPs within its structure. Just as physicians gain greater skill with experience, these practitioners will gain great skill in many aspects of primary care as their experience 
develops over time. However, the underlying knowledge base and formative clinical experience cannot be shortcut. Not knowing what one doesn't know can be dangerous to the public. On the physician side, we would never allow a 2 nd- or 3 rd-year medical student (who would have the equivalent amount of training as an ARNP), to evaluate and manage patients independently. Though states may pass laws that allow other providers with less training to practice independently, it doesn't change the reality that without competent physician supervision, we are lowering the standard of acceptable primary care and creating a 2-tiered system of access for our community.

Todd Shaffer, MD, MBA, Michael Tuggy, MD

Stoney Abercrombie, $M D_{i}$ Sneba Chacko, MDi

Joseph Gravel, MDi, Karen Hall, MD,

Grant Hoekzema, MDi Lisa Maxwell, MD,

Michael Mazzone, MD, and Martin Wieschbaus, MD

\section{References}

1. Ramas M-E. Texas Academy of Family Physicians (TAFP) Policy Brief. The question of independent diagnosis and prescriptive authority for advanced practice registered nurses in Texas: is the reward worth the risk? Feb 16, 2011;1-8. http://www.tafp.org/Media/Default/Downloads/advocacy/scope-ramas.pdf.

2. AAFP Government Relations. Talking Points: Primary Care Workforce Distribution Data. Washington, DC: AAFP Government Relations.

3. Wulfers M. The case for cooperative health care delivery. Southeast Missourian. Feb 8, 2012. http://www.semissourian.com/story/1813267. html? response $=$ no.

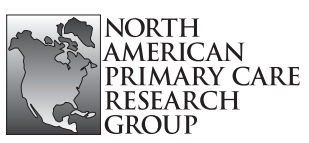

From the North American

Primary Care Research Group

Ann Fam Med 2012;10:271-272. doi:10.1370/afm.1410

\section{AN UPDATE FROM THE COMMITTEE FOR THE ADVANCEMENT OF THE SCIENCE OF FAMILY MEDICINE}

The Future of Family Medicine Project identified 10 strategic initiatives to be executed by the organizations that make up the "family" of family medicine. NAPCRG was charged with "enhancing the science of family medicine." In response to this charge, NAPCRG formed a new committee in 2008, the Committee for the Advancement of the Science of Family Medicine (CASFM). This committee has produced published articles and white papers, held workshops and created alliances, and sponsored workshops at national and international meetings. The Committee currently has 4 workgroups: Practice-Based Research, Health Informa- tion Technologies, Economic Research, and Research Methodologies. All workgroups have US and Canadian co-chairs. Membership is open and encouraged.

\section{Updates From the 4 Workgroups:}

Practice-Based Research (PBR) Workgroup

NAPCRG has been awarded a grant from AHRQ

to hold a conference for practice-based research networks. (This conference had been an AHRQsponsored meeting that has been discontinued.) This conference will be held June 20-21, 2012 in Bethesda, Maryland. Registration can be found at http://www. napcrg.org. The PBR Work Group will be helping to review submissions to this conference.

US members of the group are collaborating with Canadian researchers to increase the use of practice facilitators within practice-based research networks. The Canadian Institute for Health Research is developing a practice facilitation toolkit. AHRQ has a practice facilitation manual with an emphasis on implementing the $\mathrm{PCMH}$.

A member of the group participated in the MOVE/ BOUGE January 2012 workshop on developing effective research strategies for effective knowledge transfer (KT) in primary care. Objectives included: (1) effective transdisciplinary knowledge exchange between stakeholders and researchers and, (2) the development of an international collaborative research team grant focused on effective KT related to chronic diseases and vulnerable populations.

Another workgroup member is co-authoring a paper comparing practice-based research networks and experimental farm stations.

Health Information Technology Workgroup The workgroup on Health Information Technology is working on a second white paper entitled, "Beyond meaningful use: EHRs and primary care." The paper, intended for publication, will focus on additional features that should be added to EHRs to make them more helpful in primary care settings in the future for both clinical practice and research.

\section{Research Methodology Workgroup}

This newly formed workgroup will focus its attention initially on methodologies suitable for studying delivery system design innovations. An interactive website is envisioned.

\section{Economic Research Workgroup}

This Work Group will assist in the planning of a second NAPCRG workshop on the economic analyses involved in the study of primary care practice transformation. 